\title{
Intraindividual consistency on a cross-modality matching task
}

\author{
JAMES K. WALSH AND CARL P. BROWMAN \\ St. Louis University, St. Louis, Missouri 63103
}

\begin{abstract}
Three observers matched tone bursts and flashes for stimulus magnitude. Matches were made by each observer during 14 sessions over a 2 -month period. No intraindividual differences in power function exponents were found. Power function exponents for individuals seem to remain constant across many repetitions of this psychophysical task.
\end{abstract}

Investigations of the stability of psychophysical power function exponents produced by an individual have inconclusive results. For example, Teghtsoonian and Teghtsoonian (1971), recording magnitude estimations of visual area, suggest that exponents from an individual on this task are not stable if the time period between testing is $24 \mathrm{~h}$ or longer. In contrast, Logue (1976) reports a correlation between the exponents produced by individuals in two sessions using magnitude estimation of loudness. McGill (1960) has shown that loudness functions for individuals can be reproduced rather well. In this study, subjects estimated loudness in two sessions by indicating the distance on a line that represented the loudness of a tone. Similarly, Luce and Mo (1965) present data which suggest a fairly high degree of stability in heaviness functions produced by magnitude estimation. Cross-modality matching studies suggest that individual observers can produce consistent exponents (Lilienthal \& Dawson, 1976; Wanschura \& Dawson, 1974). In each of these studies, observers were tested two to six times to evaluate the reliability of individual psychophysical function exponents. Although these studies often report a correlation between exponents produced by an individual, the extent of exponent stability is still questionable.

Power function exponents for a single observer should remain fairly constant over time if exponent values are more closely related to sensory system properties than to non-sensory factors. Acceptance of individual power function exponents as accurate indications of sensory transduction requires that they be shown to endure within the individual over many sessions under constant conditions. The present study examined the performance of individuals on a cross-modality matching task. Fourteen power function exponents, obtained from data collected over a period of at least 2 months, were computed for each subject.

This research was supported in part by Grant $5 \mathrm{R01} \mathrm{OH}$ 00395-02 from the National Institute for Occupational Safety and Health.

\section{METHOD}

\section{Subjects}

Three males, with a mean age of 26 years, volunteered to serve as observers. Each was a psychology student without apparent visual or auditory deficits. One observer (03) had knowledge of the stimulus conditions, although he was not aware of the order of presentation used for his testing. The other two observers were naive in regard to stimulus conditions and order of presentation.

\section{Apparatus}

The stimulation system has been described in detail by Tepas (1974). Auditory and visual stimulus presentation was initiated by Tektronix waveform and pulse generators. These generators triggered Grason-Stadler Series 1200 modules, which controlled the output of a Hewlitt-Packard function generator so that $50-\mathrm{msec}$ tone bursts of $1,000 \mathrm{~Hz}$ were presented once per second through matched TDH-39 earphones. The rise-fall times of these binaural tone bursts were $10 \mathrm{msec}$. Acoustical calibration was performed at the earphones using a Brüel and Kjaer 158 sound-level meter.

The modules also controlled a stepper motor shutter in a twochannel Maxwellian view optical system. The monocular flashes were presented to the observer, who used a bite board bearing his dental impression as an aid in maintaining fixation. A tungsten ribbon filament lamp supplied light to both the target and surround channels. The target channel was used to present $50-\mathrm{msec}$ white flashes with rise-fall times of 7 and $9 \mathrm{msec}$. The second channel presented a constant $17^{\circ}$ circular surround of $400 \mathrm{~nm}$ with a half bandwidth of $21 \mathrm{~nm}$. A constant current of $18 \mathrm{~A}$ was applied to the lamp from storage batteries, and flash luminance was varied by placing fixed-value Oriel neutral density filters in the target channel. The white, circular target subtended a visual angle of $1.5^{\circ}$, and the maximum retinal illuminance available was $5.0 \mathrm{log}$ trolands (Td), as measured with a Macbeth illuminometer. The surround matched the target for brightness when approximately 3.2 log units of neutral density filtering was placed in the target channel.

Flashes and tone bursts had identical onset and offset times. This was determined by simultaneously averaging the voltage produced by a photocell placed in the position of the observer's eye and the auditory signal using a LAB-8 computer system (Tepas, 1974).

\section{Procedure}

Each observer participated in three training sessions to become familiar with the brightness-loudness matching task. A training session consisted of 20 trials which were identical in nature to those used in experimental sessions. Following training, observers were tested in 14 experimental sessions designed to produce a matching function for each session. Intersession intervals were 
irregular and ranged from a minimum of $20 \mathrm{~h}$ to a maximum of 17 days. The median intersession interval was 3.5 days. Each session was a replication of the previous session in that the same number of trials were administered.

A trial consisted of a series of flash-tone pairs presented once a second in blocks of 10 . After each block of 10 pairs, the observer made a match/no-match response via a hand-held signal button. At that time, tone intensity was either increased or decreased by $2 \mathrm{~dB}$ and the next block of 10 flash-tone pairs was presented. This procedure was continued until the observer had made at least one "match" response and two subsequent "no-match" responses. The flash intensity was then changed and a new trial was begun. In all cases, the experimenter adjusted both the auditory and visual stimulus levels. The same 10 flash luminances were used in each session. Intensities were equally spaced in .2 log unit steps. The maximum illuminance used was $4.2 \log \mathrm{Td}$. For all 10 intensities, 2 ascending and 2 descending trials were employed during each session. Therefore, a total of 40 trials were completed in a session. The order in which the trials were administered varied from session to session in a random manner not disclosed to any of the observers. At the start of each session, the observer was adapted to the dark for $10 \mathrm{~min}$.

For each trial, the initial auditory stimulus level was pseudorandomly selected in the following manner. The average match value of similar direction trials at a particular luminance from the previous session was noted. The initial value was then determined by randomly beginning from 1 to 9 steps $(2$ to $18 \mathrm{~dB}$ ) above or below that value.

Trials in which it was unlikely that a match would be made (based on previous matches) were inserted randomly as control trials, on an average of 1 every 15 trials. In addition, auditory intensities were repeated within a trial as a further control. This procedure was used about four or five times each session.

\section{RESULTS}

The control trials clearly resulted in observer responses confirming that proper care had been taken to eliminate biased matching behavior. For example, no matches were signaled on trials designed to minimize the occurrence of a match. This suggests that the observers did not respond randomly and were not "pressured" to signal a match within a certain number of flash-tone pairings. Repetition of auditory intensities within a trial produced the same match/ no-match response as the previous trial in more than
$92 \%$ of all cases. This result suggests that observers did not anticipate responses based on information from previous trials.

Means of the auditory matching values were computed for each light intensity for each session. These mean values and the 10 light intensities were fitted by linear regression lines using the method of least squares. Table 1 lists the exponents, standard error of the exponents, and the correlation coefficients for all 14 sessions for each observer. The highest and lowest exponents for each observer were not significantly different, $\mathrm{t}(16)=1.12,1.29,1.71, \mathrm{p}>.1$.

Figure 1 displays matching functions for all 14 sessions from one observer (01). Power functions describe the data well in all cases. The same general relation is apparent in Figures 2 and 3, which display the data from the other observers. The adequacy with which the data are described by power functions is indicated by the high average correlation coefficients, which are $.982, .988$, and .987 for the three observers. This suggests that, in each case, over $96 \%$ of the matching performance variability was accounted for by flash intensity.

\section{DISCUSSION}

One specific item should be mentioned before a more general discussion is undertaken. As seen in Figure 1, Flash Stimulus Level 4 (Level 1 is the most intense, Level 10 the least) was frequently perceived by Observer 01 as being brighter than Level 5 , and Level 3 was sometimes perceived to be brighter than Level 4. Similar judgments were made by Observers 02 and 03 . Most likely, these seemingly inconsistent matches are attributable to Bloch's law. That is, the flash duration used, $50 \mathrm{msec}$, falls in the duration range in which brightness is a product of duration and luminance. For a 50 -msec flash, brightness should not increase linearly with luminance, and the matching data of all observers suggest that it did not.

Table 1

Exponents, Standard Errors of Exponents, and Correlation Coefficients for All Sessions and Observers

\begin{tabular}{|c|c|c|c|c|c|c|c|c|c|c|c|c|c|c|c|}
\hline & & \multicolumn{14}{|c|}{ Session } \\
\hline & & 1 & 2 & 3 & 4 & 5 & 6 & 7 & 8 & 9 & 10 & 11 & 12 & 13 & 14 \\
\hline 01 & $\begin{array}{l}\mathrm{m} E_{\mathrm{m}} \\
\mathrm{r}\end{array}$ & $\begin{array}{l}.80 \\
.06 \\
.98\end{array}$ & $\begin{array}{l}.77 \\
.06 \\
.97\end{array}$ & $\begin{array}{l}.77 \\
.08 \\
.96\end{array}$ & $\begin{array}{l}.80 \\
.08 \\
.96\end{array}$ & $\begin{array}{l}.80 \\
.09 \\
.95\end{array}$ & $\begin{array}{l}.80 \\
.06 \\
.98\end{array}$ & $\begin{array}{l}.80 \\
.07 \\
.97\end{array}$ & $\begin{array}{l}.81 \\
.05 \\
.98\end{array}$ & $\begin{array}{l}.89 \\
.07 \\
.97\end{array}$ & $\begin{array}{l}.86 \\
.05 \\
.98\end{array}$ & $\begin{array}{l}.86 \\
.06 \\
.98\end{array}$ & $\begin{array}{l}.92 \\
.06 \\
.98\end{array}$ & $\begin{array}{l}.89 \\
.05 \\
.99\end{array}$ & $\begin{array}{l}.84 \\
.06 \\
.98\end{array}$ \\
\hline 02 & $\begin{array}{l}\mathrm{m} \\
\mathrm{SE} \\
\mathrm{m}\end{array}$ & $\begin{array}{r}1.01 \\
.05 \\
.99\end{array}$ & $\begin{array}{r}1.02 \\
.06 \\
.99\end{array}$ & $\begin{array}{r}1.09 \\
.05 \\
.99\end{array}$ & $\begin{array}{r}1.09 \\
.06 \\
.99\end{array}$ & $\begin{array}{r}1.09 \\
.05 \\
.99\end{array}$ & $\begin{array}{r}1.13 \\
.04 \\
.99\end{array}$ & $\begin{array}{r}1.11 \\
.04 \\
.99\end{array}$ & $\begin{array}{r}1.15 \\
.06 \\
.99\end{array}$ & $\begin{array}{r}1.09 \\
.04 \\
.99\end{array}$ & $\begin{array}{r}1.04 \\
.05 \\
.99\end{array}$ & $\begin{array}{r}1.10 \\
.04 \\
.99\end{array}$ & $\begin{array}{r}1.11 \\
.03 \\
.99\end{array}$ & $\begin{array}{r}1.10 \\
.04 \\
.99\end{array}$ & $\begin{array}{r}1.15 \\
.04 \\
.99\end{array}$ \\
\hline 03 & $\begin{array}{l}\mathrm{m} \\
\mathrm{SE} E_{\mathrm{m}}\end{array}$ & $\begin{array}{l}.81 \\
.05 \\
.99\end{array}$ & $\begin{array}{l}.73 \\
.06 \\
.97\end{array}$ & $\begin{array}{l}.73 \\
.06 \\
.97\end{array}$ & $\begin{array}{l}.78 \\
.03 \\
.99\end{array}$ & $\begin{array}{l}.76 \\
.04 \\
.99\end{array}$ & $\begin{array}{l}.79 \\
.03 \\
.99\end{array}$ & $\begin{array}{l}.76 \\
.06 \\
.98\end{array}$ & $\begin{array}{l}.76 \\
.04 \\
.99\end{array}$ & $\begin{array}{l}.71 \\
.05 \\
.98\end{array}$ & $\begin{array}{l}.78 \\
.03 \\
.99\end{array}$ & $\begin{array}{l}.81 \\
.03 \\
.99\end{array}$ & $\begin{array}{l}.82 \\
.05 \\
.99\end{array}$ & $\begin{array}{l}.81 \\
.03 \\
.99\end{array}$ & $\begin{array}{l}.75 \\
.03 \\
.99\end{array}$ \\
\hline
\end{tabular}

Note $-r=.765(p<.01)$. 


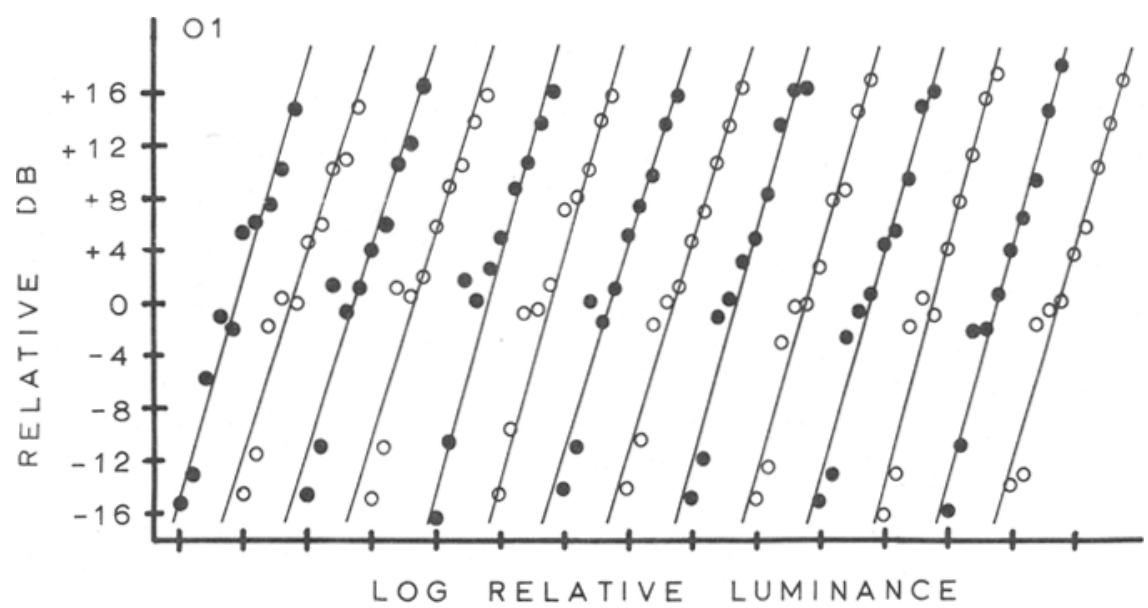

Figure 1. Cross-modality matching functions for 14 sessions for one observer (01). Functions are plotted in the order in which they were collected, with Session 1 furthest to the left. The functions are displaced horizontally to facilitate visual inspection. Hatch marks on the abscissa represent log units of relative luminance.

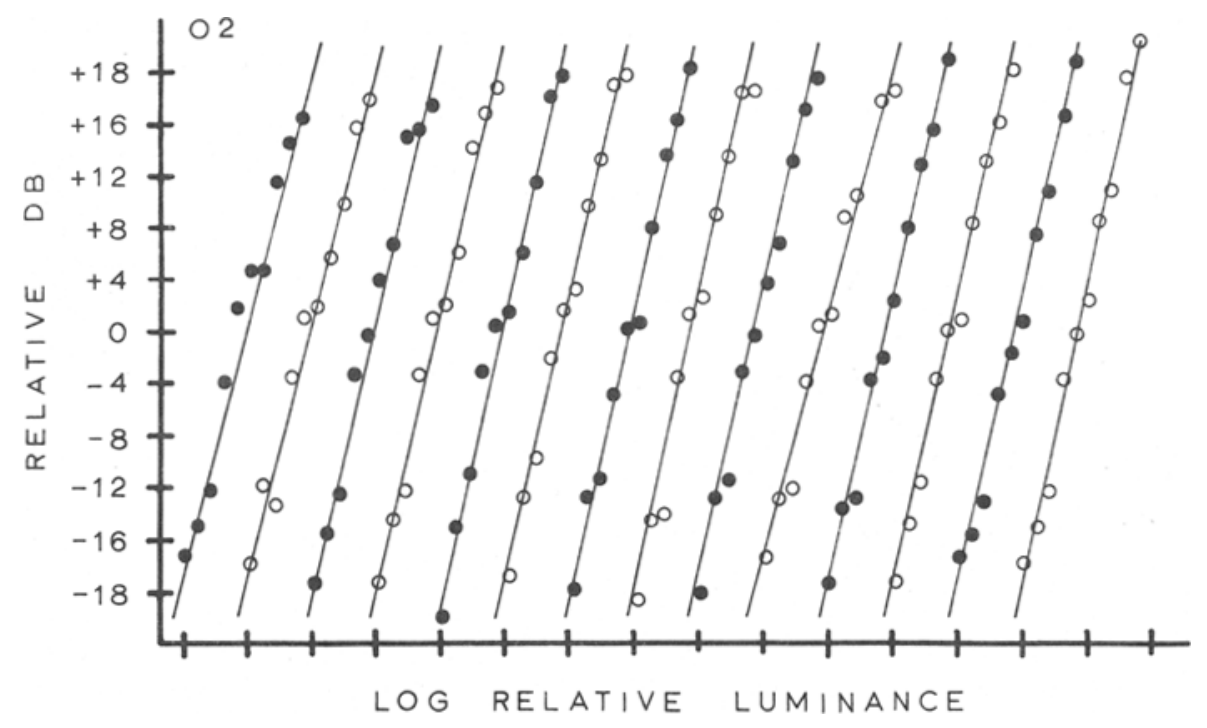

Figure 2. Cross-modality matching functions for Observer 2. Data are plotted as in Figure 1.

The data clearly indicate that the performance of individuals on this cross-modality matching task can be described by a power function. Moreoever, power function exponents for individuals remain constant over many testing sessions and fairly long intersession intervals. The exponents reported here are in reasonable agreement with other reported loudnessbrightness matching exponents (J. C. Stevens \& Marks, 1965), considering the differences in testing and stimulus conditions.

If power function exponents are to be related to sensory processes, it seems reasonable to suggest that potential sources of variability must be controlled to demonstrate exponent stability. The strategies used in the present study were aimed at minimizing variability due to non-sensory factors.

Employment of a Maxwellian view optical system controlled retinal locus of stimulation, target luminance, and light scatter. The level of dark adaptation was also held constant across sessions. Use of earphones prevented auditory stimulus distortion, resulting from changes in head position and sound absorption. In addition, frequent calibration of both the visual and auditory systems assured constant stimulus generation. These strategies resulted in stable testing conditions. Studies which do not control these 


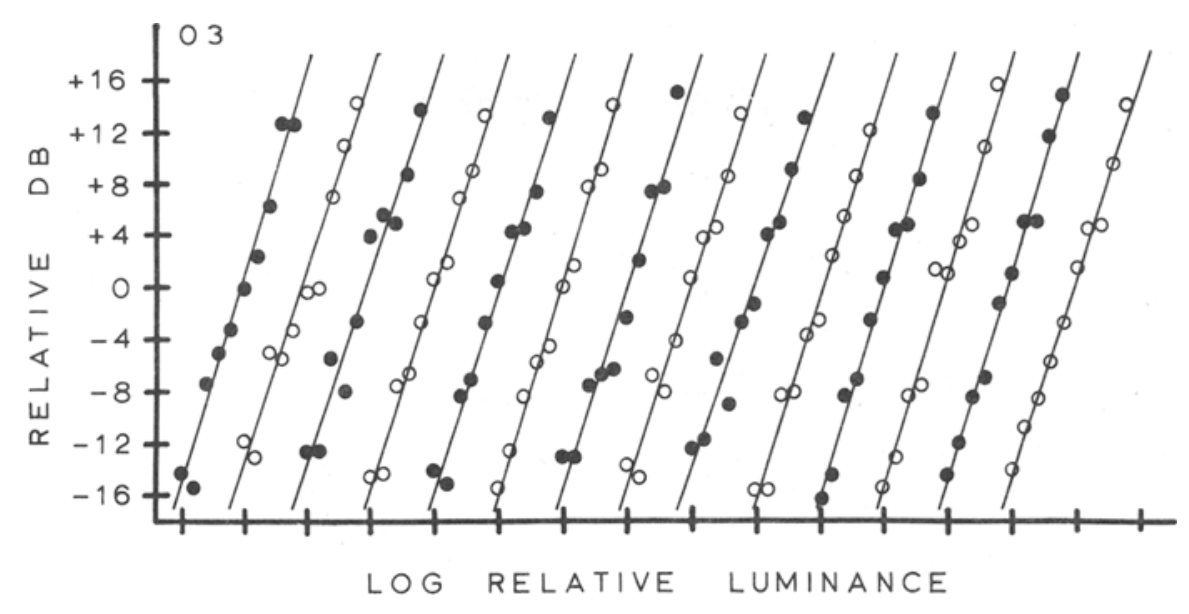

Figure 3. Cross-modality matching functions for Observer 3. Data are plotted as in Figure 1.

factors may as a result have undesirable variability in stimulus parameters at the receptor organ level. Exponent variability due to session-to-session differences in stimulus parameters may produce the incorrect suggestion that individual exponents are not stable.

In the present study, each stimulus condition was presented four times each session in an attempt to minimize the effect of random response variability. It might be argued that each stimulus condition should be presented only once within a session, since previous responses to a particular condition might influence the response on a later trial with the same stimulus condition. We feel that differentiation of stimulus conditions and the recollection of previous responses were difficult, if not impossible, in the present study. This conclusion is supported by several factors. Both visual and auditory intensities were controlled by the experimenter. Stimuli were manipulated in very small increments. The initial auditory intensity of a trial was varied across trials having the same flash intensity. Questioning of the observers at the end of the study indicated that they sometimes could not discriminate between ascending and descending trials. When asked how many light intensities were used in the study, the two naive observers guessed that there were 4 to 6 flash levels used rather than 10 . These subjective reports strongly suggest that stimulus levels were not easily recognized or recalled for later use.

Loudness and brightness were selected as matching continua because these dimensions are not typically considered or described in relation to a third continua. For example, duration or length are continua that easily can be thought of in terms of seconds or inches. These associations would seem to increase the influence of non-sensory factors upon matching performance. That is, the matching of some continua may involve judgments which are based more on "pure" sensory cues with little cognitive association, whereas for other continua it may be difficult to eliminate the influence of such associations.

This study, along with others, demonstrates that for some testing conditions power function exponents are repeatable, enduring, and characteristic of individuals. We feel that this exponent stability is the result of a minimization of many non-sensory influences upon matching judgments combined with a high level of stimulus control. The failure to demonstrate stable individual exponents in other experiments may reflect a difficulty in eliminating nonsensory factors and/or poor stimulus control.

Exponent stability alone, however, is not sufficient to claim that transducer function is the primary determinant of the exponents. As has been pointed out by several authors (S. S. Stevens, 1971; Teghtsoonian \& Teghtsoonian, 1971; Wanschura \& Dawson, 1974), a wide range of exponents among individuals probably cannot be totally accounted for by the small interindividual variation in normal transducer functioning. In the present study, the small differences between the exponents of Observers 01 and 03 might be the result of slightly different transducer function. However, the exponents of 02 are substantially disparate from those of the other two observers. This difference most likely cannot be solely attributed to the variability of normal sense organ function. Presumably, then, one or more sources of exponent variability remain to be identified. Much of this additional variability would seem to be consistent and enduring features of individuals; otherwise, the present demonstration of exponent stability would be very unlikely. In order to identify these other sources of interindividual exponent variability, it is important to minimize intraindividual variability. 
In conclusion, the elimination of many nonsensory sources of variability can promote consistent intraindividual cross-modality matching performance. This is not to say that psychophysical function exponents are "pure" reflections of transducer function, but does suggest that much of the intraindividual exponent variability reported in the literature may be related to unintentional alterations in experimental conditions. Differences in exponents among individuals should be examined in studies which minimize intraindividual variability for the purpose of identifying factors other than sensory functioning which contribute to psychophysical function exponents.

\section{REFERENCES}

Lilienthal, M. G., \& Dawson, W. E. Inverse cross-modality matching: A test of ratio judgment consistency for group and individual data. Perception \& Psychophysics, 1976, 19, 252-260.

LOGUE, A. W. Individual differences in magnitude estimation of loudness. Perception \& Psychophysics, 1976, 19, 279-280.
LUCE, R. D.. \& Mo, S. S. Magnitude estimation of heaviness and loudness by individual subjects: A test of a probabilistic response theory. The British Journal of Mathematical and Statistical Psychology, 1965, 18, 159-174.

McGill, W. The slope of the loudness function: A puzzle. In H. Gulliksen \& S. Messick (Eds.), Psychological scaling: Theory and applications. New York: Wiley, 1960.

Stevens, J. C., \& Marks, L. E. Cross-modality matching of brightness and loudness. Proceedings of the National Academy of Science, 1965, 54, 407-411.

Stevens, S. S. Issues in psychophysical measurement. Psychological Review, 1971, 78, 426-450.

Teghtsoonian, M., \& Teghtsoonian, R. How repeatable are Stevens' power law exponents for individual subjects? Perception \& Psychophysics, 1971, 10, 147-149.

TEPAS. D. I. Computer analysis of the electroencephalogram: Evoking, promoting, and provoking. Behavior Research Methods \& Instrumentation, 1974, 6, 95-110.

Wanschura, R. G., \& Dawson, W. E. Regression effect and individual power functions over sessions. Journal of Experimental Psychology, 1974, 102, 806-812.

(Received for publication September 27, 1977; revision accepted November 24, 1977.) 